\title{
A20 protein regulates lipopolysaccharide-induced acute lung injury by downregulation of NF-кB and macrophage polarization in rats
}

\author{
YING WANG $^{1 *}$, ZHENJU SONG $^{2 *}$, JING BI $^{1}$, JIE LIU $^{1}$, LIN TONG $^{1}$, \\ YUANLIN SONG ${ }^{1}$, CHUNXUE BAI $^{*}$ and XIAODAN ZHU ${ }^{1 *}$ \\ ${ }^{1}$ Department of Pulmonary Medicine; ${ }^{2}$ Emergency Department, Zhongshan Hospital, Fudan University, \\ Shanghai Respiratory Research Institute, Shanghai 200032, P.R. China
}

Received October 12, 2016; Accepted June 8, 2017

DOI: $10.3892 / \mathrm{mmr} .2017 .7184$

\begin{abstract}
Modulation of inflammation is a crucial component of the development of acute lung injury. A20, a ubiquitin editing enzyme, may regulate cellular inflammatory reactions, particularly those involving the signaling pathway of nuclear factor $N F-\kappa B(N F-\kappa B)$. The present study investigated the mechanism by which A20 downregulated NF- $\kappa$ B and further contributed to macrophage polarization from the M1 to M2 phenotypes in lipopolysaccharide (LPS)-induced lung injury. Sprague-Dawley rats injected with LPS were used in the present study. Bronchoalveolar lavage fluid and lung tissue were collected from each experimental rat. A macrophage cell line was used to test the expression levels of A20. Tumor necrosis factor- $\alpha$ (TNF- $\alpha$ ), interleukin-1 beta (IL-1 $\beta)$ and NF- $\kappa \mathrm{B}$ activities were assessed by ELISA and polymerase chain reaction. Macrophage phenotypes were assayed using fluorescence-activated cell sorting. Elevated levels of TNF- $\alpha$, IL-1 $\beta, N F-\kappa B$ and A20 were observed in the macrophages of rats treated with LPS. Furthermore, A20 overexpression inhibited NF- $\kappa \mathrm{B}$ DNA binding activity and increased macrophage polarization from the M1 to M2 phenotype in lung macrophages of the NR8383 cell line. It was concluded
\end{abstract}

Correspondence to: Dr Chunxue Bai or Dr Xiaodan Zhu, Department of Pulmonary Medicine, Zhongshan Hospital, Fudan University, Shanghai Respiratory Research Institute, 180 Fenglin Road, Shanghai 200032, P.R. China

E-mail: chunxue.bai@zs-hospital.sh.cn

E-mail: dan_yt@126.com

*Contributed equally

Abbreviations: ALI, acute lung injury; ARDS, acute respiratory distress syndrome; LPS, lipopolysaccharide; TNF- $\alpha$, tumor necrosis factor $\alpha$; RT-qPCR, reverse transcription quantitative-polymerase chain reaction

Key words: acute lung injury, LPS, A20 protein, nuclear factor $\mathrm{NF}-\kappa \mathrm{B}$, macrophage that the A20 protein in macrophages modulates lung injury induced by LPS. The overexpression of A20 in macrophages may be involved in modulating macrophage polarization. The mechanisms and molecular identification of macrophage polarization activation may provide a basis for the treatment of inflammation in lung injury.

\section{Introduction}

According to the Berlin Definition, acute lung injury (ALI) is equal to mild acute respiratory distress syndrome (ARDS) with a partial pressure of oxygen/fraction of inspired oxygen of $<300 \mathrm{mmHg}$ and positive end expiratory pressure/continuous positive airway pressure levels of $\geq 5 \mathrm{cmH}_{2} \mathrm{O}$ (1). ARDS is a common cause of mortality in patients suffering from severe pneumonia or avian influenza for example, with the mortality rate being as high as 40-60\% (2-4). Despite improvements in supportive treatment, the mortality rate of ARDS remains high $(5,6)$. In addition, there is no effective pharmacological therapy that targets ARDS directly (7). The dominant characteristics of ARDS are proteinaceous pulmonary edema with severe inflammation and gas exchange abnormalities with severe hypoxemia (8). Proinflammatory responses occur in the pathogenesis of lung injury, which indicates that inhibiting inflammatory cytokine secretion may be a therapeutic approach to inhibit the progression of inflammation in ARDS.

Lipopolysaccharide (LPS) is the main cause of ALI in animal models and has been demonstrated to modulate the nuclear factor $N F-\kappa B(N F-\kappa B)$ signaling pathway (9). The $\mathrm{NF}-\kappa \mathrm{B}$ pathway is an important signaling pathway induced by lung injury (10) and regulates several molecular processes, including apoptotic cell death, cell cycle progression, cell survival and adhesion, and the expression and activation of inflammatory factors, including tumor necrosis factor $\alpha$ (TNF- $\alpha$ ) and interleukin $1 \beta$ (IL-1 $\beta$ ) $(9,11)$. In clinical practice, activation of the NF- $\kappa \mathrm{B}$ pathway is observed in a number of inflammatory injuries, including rheumatoid arthritis and asthma $(12,13)$. Therefore, it is essential to consider the regulatory mechanism of $\mathrm{NF}-\kappa \mathrm{B}$ activity for ALI intervention.

$\mathrm{NF}-\kappa \mathrm{B}$ activity is also associated with macrophage polarization (14-16). Macrophages serve a crucial role in the 
immunomodulation of lung injury and function to eliminate invading pathogens by producing cytokines (17). This leads to the damage and impairment of lung function (18). Activated macrophages of different phenotypes are routinely classified as M1 or M2 macrophages (16). Activated M1 macrophages are immune cells of the acute inflammatory response, which produce large amounts of lymphokines and are aggressive against bacteria (19). By contrast, M2 macrophages participate in tissue repair and wound healing (15). A previous study focused on how macrophage polarization in vivo can be manipulated to alter disease outcomes (14).

Preliminary data on A20, a cytoplasmic zinc finger protein, or the A20 binding inhibitor of $N F-\kappa B$ activation families demonstrated that A20 may be involved in the downregulation of $\mathrm{NF}-\kappa \mathrm{B}$ (13). It has been demonstrated that A20 has the ability to inhibit the activity of NF- $\kappa B$ (13). In addition, A20-deficient mice demonstrate serious inflammatory responses following LPS injury, indicating that A20 may limit the inflammatory reaction through inhibition of the $\mathrm{NF}-\kappa \mathrm{B}$ response in vivo (20). Furthermore, A20 is reported to downregulate the $\mathrm{NF}-\kappa \mathrm{B}$ signaling pathway as demonstrated by overexpression in human carcinoma cells (21). Additionally, low expression of A20 may upregulate the expression of TNF- $\alpha$ in macrophages (22).

Several studies demonstrated the activity of A20 in the lung. A20 may serve an inhibitory role in inflammatory responses in airway epithelial cells (23). The studies by Tiesset et al (24) and Onose et al (25) suggest that A20 may have a protective function in the course of infections with Pseudomonas aeruginosa or influenza. However, whether the A20 protein exerts this suppressive effect on $N F-\kappa B$ and inhibits the inflammatory response induced by LPS in the lung remains unknown. Similarly, whether the A20 protein may regulate macrophage polarization remains obscure.

In the present study, it was observed that LPS-induced acute lung damage acted via the modulation and overexpression of A20 which were associated with the progression of macrophage polarization via the inhibition of the $\mathrm{NF}-\kappa \mathrm{B}$ pathway.

\section{Materials and methods}

Animal treatment. A total of 54 male specific pathogen-free Sprague-Dawley rats weighing 250-300 g (8-10 weeks) were assigned to the Laboratory Animal Center, Fudan University (Shanghai, China) in clean conditions with a controlled temperature of $18-26^{\circ} \mathrm{C}$, humidity $40-70 \%$, and $12 / 12-\mathrm{h}$ light/dark cycle. The animals were given free access to water but restricted to food only for $12 \mathrm{~h}$ prior to experimentation. The Animal Ethics Committee of Fudan University approved all experimental protocols. All animals were sacrificed following the Guide for the Care and Use of Laboratory Animals published by the National Institutes of Health.

The rats received an injection of PBS or LPS (Escherichia coli O55:B5; Sigma-Aldrich; Merck KGaA, Darmstadt, Germany; cat. no. L2637) via the tail vein. A dose of $10 \mathrm{mg} / \mathrm{kg}$ of LPS was dissolved in $1 \mathrm{ml}$ PBS. The control animals were injected with $1 \mathrm{ml}$ PBS. After 1, 2, 4, 6, 8, 12, 24 and $48 \mathrm{~h}(\mathrm{n}=6 \mathrm{each})$, the rats were treated with intraperitoneal injections of $7.5 \mathrm{ml} / \mathrm{kg}$ urethane. The wet-to-dry (W/D) weight ratio of the middle lobe of the right lung was measured as previously described (26).

Bronchoalveolar lavage fluid (BALF). BALF of each experimental rat was collected and was done in the left lung. BALF was centrifuged $\left(600 \mathrm{x} \mathrm{g}, 10 \mathrm{~min}\right.$ at $4^{\circ} \mathrm{C}$; LTPA Cytocentrifuge, Experimental Instrument Factory, Academy of Military Medical Sciences, Beijing, China), and cell-free supernatants were stored at $-80^{\circ} \mathrm{C}$. The cell pellet was diluted in PBS, and total cell number was counted with a hemocytometer. Differential cell counts were done with cytocentrifuge preparations stained with Diff-Quik stain at room temperature for $90 \mathrm{sec}$. Neutrophil populations were determined by counting 300 cells/sample, and a percentage was calculated based on 6 mice per group. Bronchoalveolar lavage protein concentration was measured in the cell-free supernatant by using a bicinchoninic acid protein assay kit according to the manufacturer's instruction (Thermo Fisher Scientific, Inc., Waltham, MA, USA).

Cell culture. The Shanghai Institutes for Biological Sciences of the Chinese Academy of Science (Shanghai, China) provided the lung macrophage NR8383 cell line from its cell bank. All cells were preserved in humidified air with $5 \% \mathrm{CO}_{2}$ at $37^{\circ} \mathrm{C}$. Dulbecco's modified Eagle's medium/F-12K (Invitrogen; Thermo Fisher Scientific, Inc.; cat. no. 12100-046) was used to preserve the cells, supplemented with $20 \%$ fetal bovine serum (Hyclone; GE Healthcare Life Sciences, Logan, UT, USA; cat. no. SV30087.02), $100 \mathrm{U} / \mathrm{ml}$ streptomycin and $100 \mathrm{U} / \mathrm{ml}$ penicillin G (Invitrogen; Thermo Fisher Scientific, Inc.; cat no. GB15140-122) with $2.5 \mathrm{~g} / 1 \mathrm{NaHCO}_{3}$ and $2 \mathrm{mM}$ L-glutamine solution (Sigma-Aldrich; Merck KGaA; cat. no. $\mathrm{G} 7513)$ at $37^{\circ} \mathrm{C}$ in humidified air with $5 \% \mathrm{CO}_{2}$.

Transfection of small interfering RNA (siRNA). Sigma-Aldrich (Merck KGaA) provided the siRNA. The sequence of siRNA for rat A20 is: Sense 5'-CCGGCCAATGGTGAT GGAAACTGCCCGAGTAGGCAGTTTCCATCACCGTTG GTTTTTG-3', and antisense 5'-AATTCAAAAACCAAT GGT GATGGAAACTGCCCGAGTAGGCAGTTTCCATCA CCGTTGG-3'. For siRNA control (scrambled siRNA, SCR), oligos with no matching GeneBank sequence were used: Sense 5'-GCGACGAUCUGCCUAAGAU-3', and antisense 5'-AUCUUAGGCAGAUCGUCGC-3'. The siRNA oligonucleotide pairs were prepared as $20 \mu \mathrm{M}$ stocks. For transient transfections, the Lipofectamine ${ }^{\mathrm{TM}}$ RNAiMAX kit (Thermo Fisher Scientific, Inc.; cat no. 13778-150) was used on the NR8383 cell line. Following transfection, the cells were left for a further $24 \mathrm{~h}$ before they were used for experiments.

A20 plasmid transfection. Mouse A20 (Tnfaip3; gene ID: NM_009397.3) was cloned from mouse cDNA (Beijing ComWin Biotech Co., Ltd.; Beijing, China) with forward primer (5'-GTTGGCAAAGCATACAACTGAAAGG-3') and reverse primer (5'-GGCTGTGACGAAGGAAGAGCTTA-3') under the following conditions: i) $95^{\circ} \mathrm{C}$ for $2 \mathrm{~min}$; ii) 30 cycles of $95^{\circ} \mathrm{C}$ for $20 \mathrm{sec}, 52^{\circ} \mathrm{C}$ for $20 \mathrm{sec}$ and $72^{\circ} \mathrm{C}$ for $60 \mathrm{sec}$; iii) $72^{\circ} \mathrm{C}$ for $3 \mathrm{~min}$. The nucleotide sequence was inserted into the pCDH-CMV-MCS-EF1-copGFP vector (System Biosciences, Palo Alto, CA, USA; cat. no. cd511b) at the EcoRI and BamHI restriction sites. The recombinant vector was transfected into the 
Table I. Primers used for polymerase chain reaction.

Sequence (5'-3')

\begin{tabular}{lllc}
\cline { 2 - 3 } Gene name & \multicolumn{1}{c}{ Forward } & \multicolumn{1}{c}{ Reverse } & Size, bp \\
\hline A20 & GCAGTGTAAAAGGCAGGCTAAC & TGGGGTTCTCTCTCGTATCTTC & 131 \\
TNF- $\alpha$ & CTGTGCCTCAGCCTCTTCTC & ACTGATGAGAGGGAGCCCAT & 126 \\
IL- $\beta$ & ATCAGCACCTCACAGCTTCC & TCTCCTCCCGATGAGTAGGC & 195 \\
$\beta$-actin & GAGATTAGTGCCCTGGCTCCTA & GACTCATCGTACTCCTGCTTGCTG & 150 \\
\hline
\end{tabular}

TNF- $\alpha$, tumor necrosis factor $\alpha$; IL- $1 \beta$, interleukin $1 \beta$.

NR8383 cell line using Lipofectamine ${ }^{\mathrm{TM}} 2000$ (Thermo Fisher Scientific, Inc.; cat. no. 11668-019). Following transfection, the cells were treated with LPS $(1 \mu \mathrm{g} / \mathrm{ml})$ at room temperature for $0.5,1,2$ and $4 \mathrm{~h}$. The cells were then collected for use.

Histopathology and immunohistochemistry. Subsequent to measurement of the wet weights and examination of the BALF, the lower lobe of the right lung was fixed in $4 \%$ formaldehyde at room temperature and paraffin-embedded with the procedure previously described (13), while the upper lobes of the right lung were stored at $-80^{\circ} \mathrm{C}$. The tissue preparations with paraffin-embedding were cut into $5-\mu \mathrm{m}$ sections and stained with hematoxylin and eosin to assess the histopathology score. The method of staining and assessment was as previously described (26). Immunostaining of lung tissue was done with $5-\mu \mathrm{m}$ paraffin sections. Anti-A20 (Cell Signaling Technology, Inc., Danvers, MA, USA; cat. no. 5630) and F4/80 (Abcam, Cambridge, UK; cat. no. ab111101) antibodies were used for staining tissue sections at different time points. Lung tissue was treated twice with fluorescently labeled antibodies; F4/80 (secondary antibody with green fluorescence) and A20 (secondary antibody with red fluorescence), while the nuclei were stained with DAPI. Fluorescent images were captured by a Zeiss LSM 510 META confocal laser-scanning microscope (Carl Zeiss AG, Oberkochen, Germany). The number of A20 and $\mathrm{F} 4 / 80$ positive cells was counted in five randomly selected fields by viewing each slide at a magnification of $\mathrm{x} 400$ and the average number in each group was calculated. All procedures were as previously described (13).

$N F-\kappa B$ DNA binding activity assay and cytokine detection. $\mathrm{NF}-\kappa \mathrm{B}$ DNA binding activity was measured in lung tissue with an ELISA kit from Active Motif (Carlsbad, CA, USA; TransAM ${ }^{\circledR}$ Flexi NFкB p65; cat. no. 40098) and the result was presented as NF- $\mathrm{KB}$ optical density (OD). The procedure was performed according to the manufacturer's protocol. TNF- $\alpha$ (Rat TNF-alpha Quantikine SixPak; R\&D Systems, Inc., Minneapolis, MN, USA; cat. no. SRTA00) and IL-1 $\beta$ (Rat IL-1 beta/IL-1F2 Quantikine SixPak; R\&D Systems, Inc.; cat. no. SRLB00) levels in the supernatant were measured with ELISA kits. The method was performed according to the manufacturer's protocol.

Western blot analysis. The procedure for immunoblotting was performed as previously described (27). Proteins were loaded into the lanes of an SDS or tricine-SDS polyacrylamide gel. The proteins were separated and transferred to nitrocellulose membranes $(0.45$ or $0.22 \mu \mathrm{m}$; Schleicher \& Schuell; BioScience GmbH, Dassel, Germany). The membranes were blocked with 5\% non-fat dry milk in 0.01 M PBS (pH 7.4) and $0.05 \%$ Tween-20 (TPBS) at room temperature for $1 \mathrm{~h}$. Subsequently, the membrane was incubated with primary antibodies directed against target proteins overnight at $4^{\circ} \mathrm{C}$. The primary antibodies used were: Anti-A20 rabbit monoclonal antibody (A20/TNFAIP3 (D13H3) Rabbit mAb; Cell Signaling Technology, Inc.; Danvers, MA, USA; cat. no. 5630), anti-NF-kB p65 (Abcam; Cambridge, UK; cat. no. ab16502) and GAPDH (R\&D Systems, Inc.; cat. no. AF5718). The final dilutions for the primary antibodies were: A20, NF-kB, 1:1,000; and GAPDH, 1:2,000. Following three quick washes in TPBS, the membranes were incubated with secondary antibodies conjugated to horseradish peroxidase (GE Healthcare, Chicago, IL, USA; cat. no. RPN4301) diluted at 1:5,000 in TPBS for $1 \mathrm{~h}$ at $4^{\circ} \mathrm{C}$. The enhanced chemiluminescence method (GE Healthcare; cat. no. RPN2106) was used to visualize protein bands. The protein expression was quantified using Quantity One software version 4.62 (Bio-Rad Laboratories Inc., Hercules, CA, USA).

RNA extraction and reverse transcription-quantitative polymerase chain reaction $(R T-q P C R)$. Total RNA was isolated from the lung tissues using TRIzol reagent (Thermo Fisher Scientific Inc.; cat. no. 15596018) and treated with RNase-free DNase I (Roche Applied Science, Penzberg, Germany; cat. no. 10104159001). First-strand cDNA was synthesized using Moloney-murine leukemia virus reverse transcriptase (Promega Corporation, Madison, WI, USA; cat. no. M1701) and oligo-dTs (Promega Corporation; cat. no. C1101), which was performed at $42^{\circ} \mathrm{C}$ for $1 \mathrm{~h}$ followed by $70^{\circ} \mathrm{C}$ for $15 \mathrm{~min}$. Subsequently, the RevertAid ${ }^{\mathrm{TM}}$ First Strand cDNA Synthesis kit (Fermentas; Thermo Fisher Scientific, Inc.) was used for the qPCR, under the following conditions: i) $95^{\circ} \mathrm{C}$ for $30 \mathrm{sec}$; ii) 40 cycles of $95^{\circ} \mathrm{C}$ for $5 \mathrm{sec}$ and $60^{\circ} \mathrm{C}$ for $30 \mathrm{sec}$. Quantitative analysis was performed with the Applied Biosystems Prism 7500 Sequence Detection System according to the manufacturer's protocol (Thermo Fisher Scientific, Inc.). The expression levels of target cDNAs were normalized to the endogenous transcription levels of the control and quantification was performed using $2^{-\Delta \Delta \mathrm{Cq}}(28)$. The primer sequences are provided in Table I. 

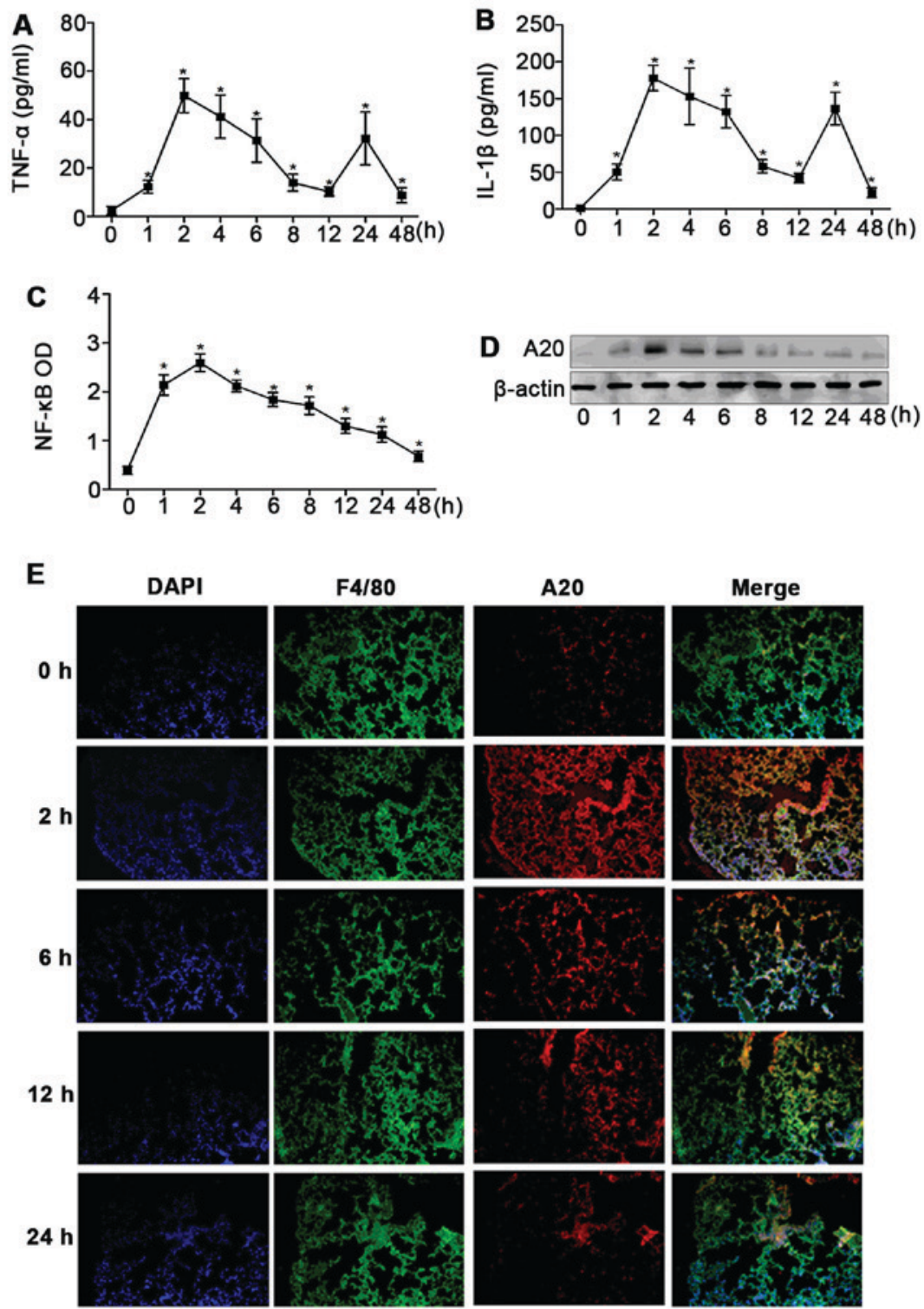

Figure 1. Analysis of TNF- $\alpha$, IL-1 $\beta$ and A20 in BALF and lung tissue. Protein levels of (A) TNF- $\alpha$ and (B) IL-1 $\beta$ in BALF for each group at $0,1,2,4,6,8$, 12,24 and $48 \mathrm{~h}$ following inoculation ( $\mathrm{n}=6$ rats/group). (C) NF- $\mathrm{KB}$ activity as analyzed by immunoblotting of BALF for each group at $0,1,2,4,6,8,12,24$ and $48 \mathrm{~h}$ following inoculation ( $\mathrm{n}=6$ rats/group). (D) The level of A20 in lung tissue for each group at $0,1,2,4,6,8,12,24$ and $48 \mathrm{~h}$ following inoculation ( $\mathrm{n}=6$ rats/group) analyzed by western blotting. (E) Immunofluorescence staining of A20 at 0,2, 6, 12 and $24 \mathrm{~h}$ following treatment with LPS. Lung tissue was labeled with 2 fluorescent tags: F4/80 (green fluorescence) and A20 (red fluorescence), while the nuclei were stained with DAPI. A20 was expressed in pulmonary macrophages. The data are presented as the mean \pm standard deviation. "P<0.05 vs. the control group. TNF- $\alpha$, tumor necrosis factor $\alpha$; IL- $1 \beta$,

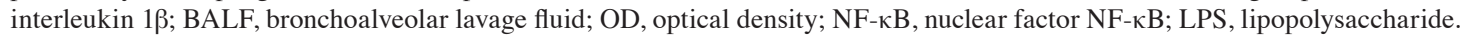

Flow cytometry. NR8383 cells were treated with trypsin, resuspended in PBS and stained with $10 \mu 1 \mathrm{~F} 4 / 80$ antibodies $\left(15 \mathrm{~min}\right.$ at $\left.37^{\circ} \mathrm{C}\right)$ or $10 \mu 1$ anti-cluster of differentiation CD206 $\left(15 \mathrm{~min}\right.$ at $\left.37^{\circ} \mathrm{C}\right)$. A20 overexpression and A20 knockdown cells [small interfering (si)RNA for A20] were treated with anti-F4/80 and CD206 antibodies. The anti-F4/80 antibody was labeled with fluorescein isothiocyanate (Abcam; cat. no. ab111101) with green fluorescence, while the anti-CD206 antibody was labeled with allopycocyanin (Abcam; cat. no. ab64693) with red fluorescence. The final dilutions for the antibodies were: Anti-F4/80 antibody, 1:100; and anti-CD206 antibody, 1:3,000. The FL2 and FL1 fluorescence was collected in each experiment by gating and acquiring the cell population using a FACScan flow cytometer (BD Biosciences, Franklin Lakes, NJ, USA). CD206 $/ \mathrm{F} 4 / 80^{+}$cells are M2 macrophages while CD206 $/ \mathrm{F} 4 / 80^{+}$cells are M1 macrophages (29).

Statistical analysis. Statistical significance was assessed by analysis of variance (ANOVA) and Student's t-test using SPSS software version 22.0 (IBM Corp., Armonk, NY, USA) and GraphPad Prism 6 (GraphPad Software Inc., La Jolla, CA, USA). One-way ANOVA was used for the analysis of relative quantitative data, with the least significant difference post hoc test. Student's t-test was used for the analysis of independent variables. The data were presented as the mean \pm standard 

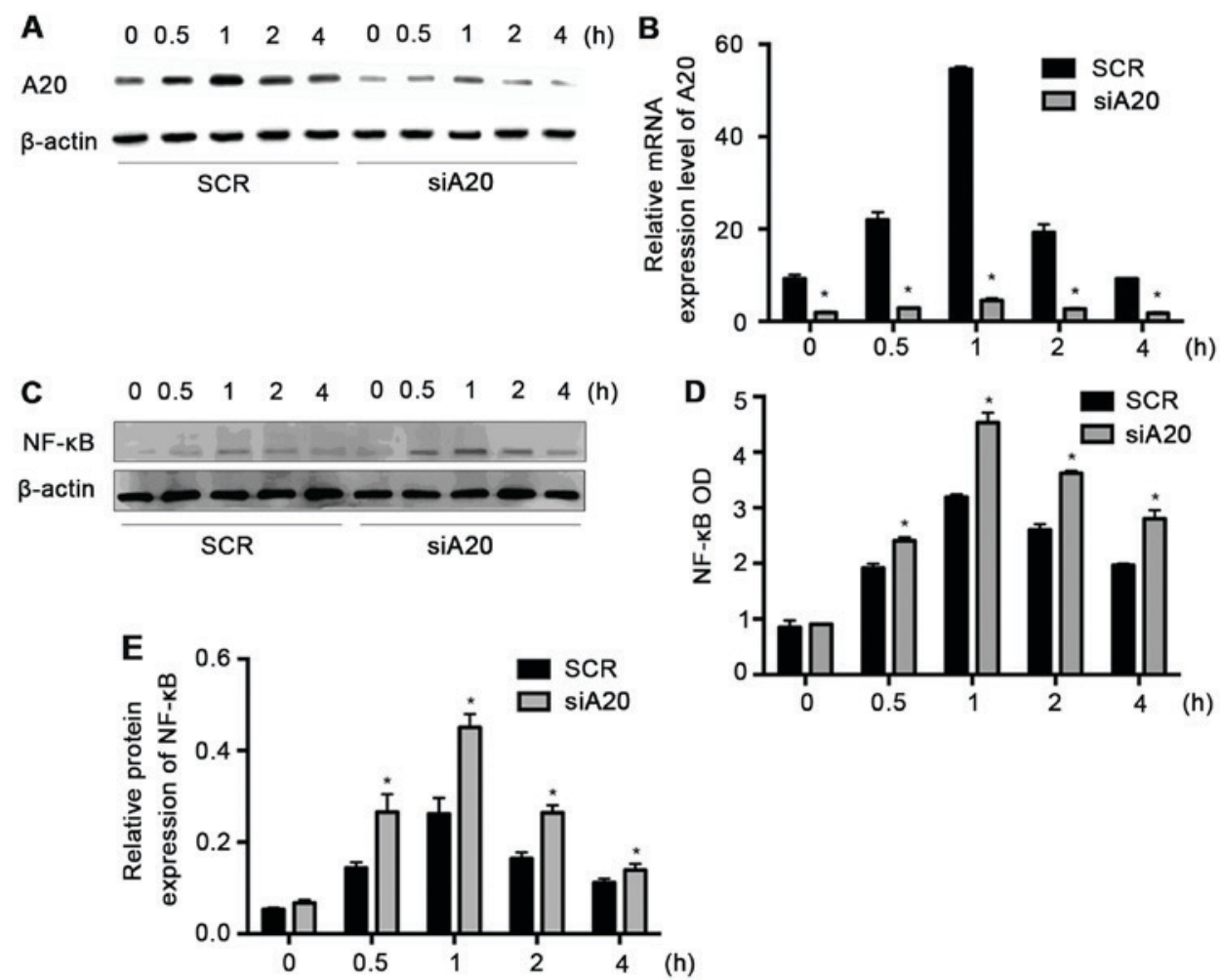

Figure 2. Effect of A20 knockdown on A20 and NF-кB expression. (A) Protein and (B) mRNA expression of A20 following treatment with SCR and siA20 was analyzed by western blotting and the reverse transcription quantitative polymerase chain reaction, respectively. (C) NF- $\mathrm{B}$ protein expression was analyzed by western blotting (D) Degree of NF- $\kappa$ B DNA binding activity was analyzed by ELISA. (E) Quantification of NF- $\kappa$ B by western blotting. The data are presented as the mean \pm standard deviation. ${ }^{*} \mathrm{P}<0.05$ vs. SCR group. SCR, scrambled; siA20, A20 small interfering RNA; NF- $\kappa \mathrm{B}$, nuclear factor NF- $\kappa$.

deviation. $\mathrm{P}<0.05$ was considered to indicate a statistically significant difference.

\section{Results}

LPS induces acute lung injury in rats. Compared with the control group, the LPS-treated group demonstrated histological features representative of ALI and significant increases in the lung W/D weight ratio, BALF total cell number and BALF protein concentration $(\mathrm{P}<0.05$; data not shown).

Cytokine secretion and NF- $\mathrm{B}$ DNA binding activity are increased by LPS. Following LPS treatment, the levels of TNF- $\alpha$ and IL-1 $\beta$, and NF- $\kappa$ B DNA binding activity increased in a time-dependent manner (Fig. 1A-C). At the $2 \mathrm{~h}$ time-point, the activity reached a first peak (all $\mathrm{P}<0.05$ compared with the control group). In the following $10 \mathrm{~h}$, the levels of TNF- $\alpha$ and IL- $1 \beta$, and the NF- $\kappa \mathrm{B}$ activity decreased gradually but remained increased compared with the control (all $\mathrm{P}<0.05$ ). Furthermore, at $24 \mathrm{~h}$, the levels of TNF- $\alpha$ and IL-1 $\beta$ increased again (both $\mathrm{P}<0.05$ compared with the control group).

LPS regulates A20 expression in pulmonary tissues. Following treatment with LPS, the mRNA (data not shown) and protein levels of A20 in the lung tissue increased with time (Fig. 1D) and peaked after $2 \mathrm{~h}(\mathrm{P}<0.05$ compared with the control group). Subsequently, the levels gradually decreased but were increased compared with the control group $(\mathrm{P}<0.05)$. As demonstrated by immunofluorescence staining, the level of A20 also peaked at $2 \mathrm{~h}$ and gradually decreased following treatment with LPS, and A20 was expressed in pulmonary macrophages (Fig. 1E).

A20 siRNA increases $N F-\kappa B$ DNA binding activity and upregulates $T N F-\alpha$ and $I L-1 \beta$ secretion. To examine the transfection efficiency, the mRNA and protein expression levels of A20 were measured by RT-qPCR and western blotting, respectively. A20 expression was significantly inhibited in the siA20 (A20 small interfering RNA) group compared with the SCR group throughout (Fig. 2A and B). Following induction by LPS, the NF- $\kappa \mathrm{B}$ DNA binding activity and protein expression levels increased in the A20-knockdown macrophages; the highest levels were observed at 1 h (Fig. 2C-E). Subsequently, these levels gradually decreased.

The mRNA levels of TNF- $\alpha$ and IL- $1 \beta$ increased in the A20-knockdown macrophages induced by LPS, and they reached peak levels at $1 \mathrm{~h}$ (Fig. 3A and B). Subsequently, they gradually reduced. These results were the same as the protein levels of TNF- $\alpha$ and IL-1 $\beta$ measured by ELISA (Fig. 3C and D).

A20 overexpression inhibits $N F-\kappa B$ DNA binding activity, and decreases TNF- $\alpha$ and $I L-1 \beta$ secretion. To examine the transfection efficiencies, the mRNA and protein expression levels of A20 were measured by RT-qPCR and western blotting, respectively. When compared with vehicle control (VEC), A20 expression was markedly increased (Fig. 4A and $\mathrm{B})$. NF- $\kappa \mathrm{B}$ protein expression increased in VEC macrophages 

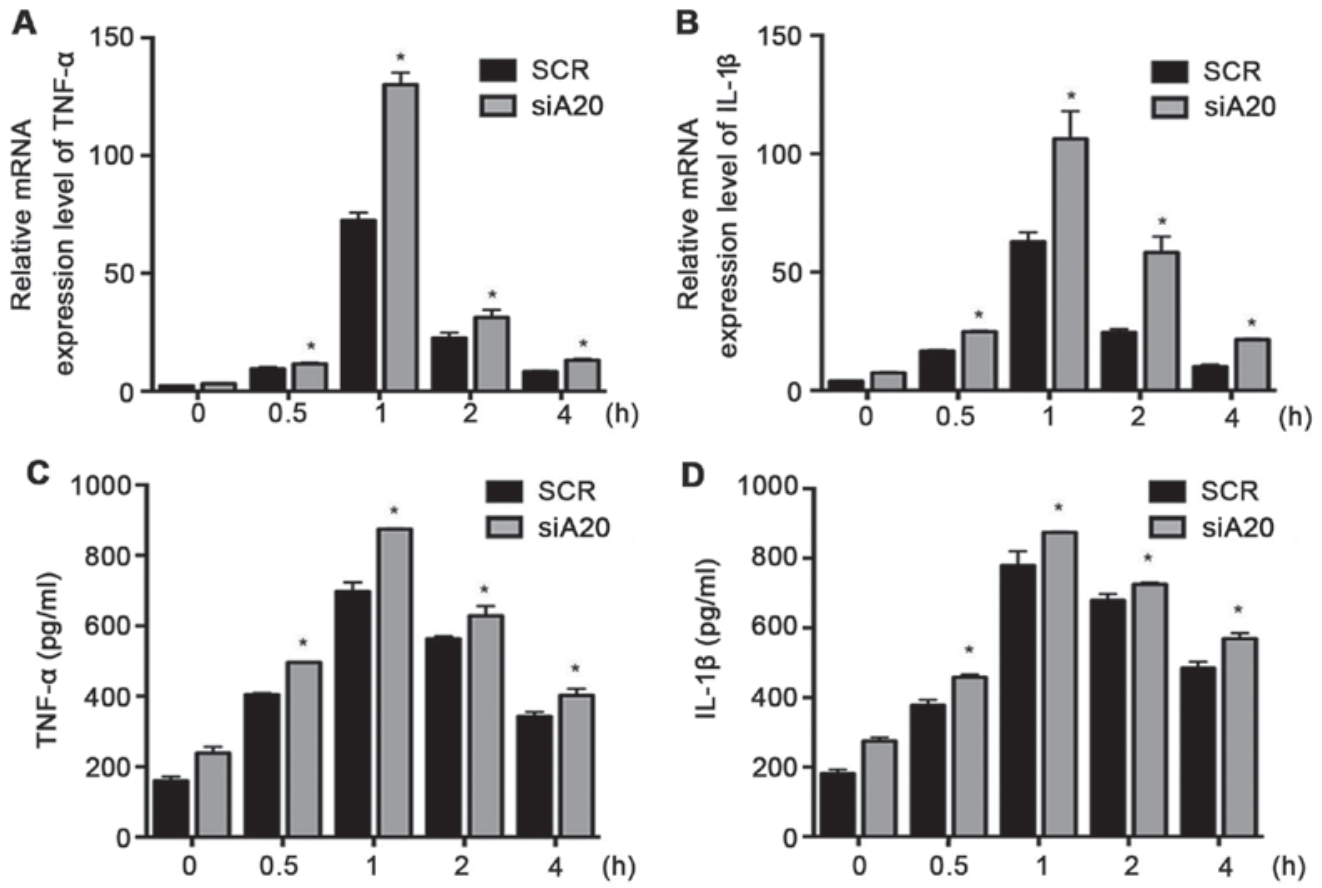

Figure 3. Effect of A20 knockdown on TNF- $\alpha$ and IL-1 $\beta$. mRNA levels of (A) TNF- $\alpha$ and (B) IL-1 $\beta$ were analyzed using the reverse transcription quantitative polymerase chain reaction. Protein levels of (C) TNF- $\alpha$ and (D) IL-1 $\beta$. The data are presented as the mean \pm standard deviation. "P<0.05 vs. SCR group. TNF- $\alpha$, tumor necrosis factor $\alpha$; IL-1 $\beta$, interleukin $1 \beta$; SCR, scrambled; siA20, A20 small interfering RNA.
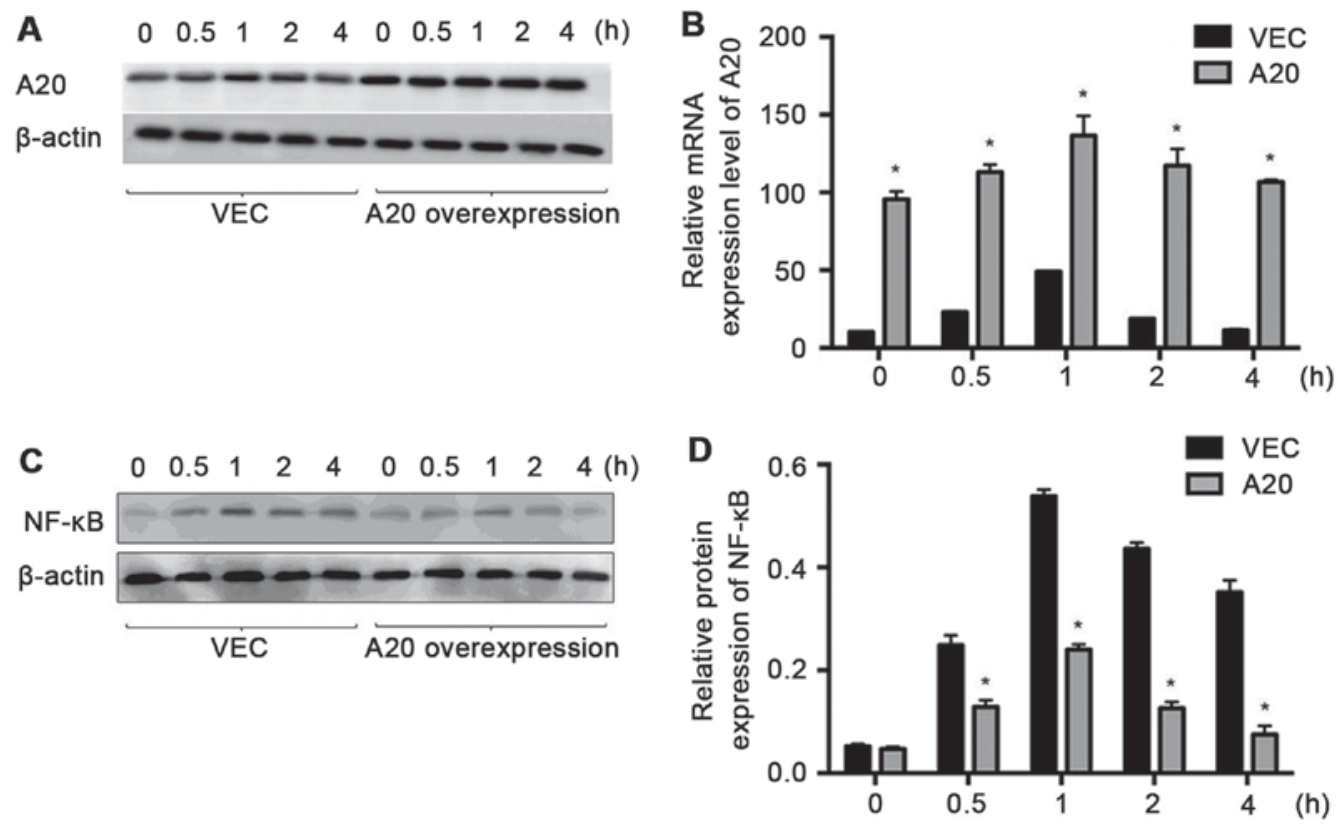

Figure 4. Effect of A20 overexpression on A20 and NF- $\kappa$ B. (A) Protein and (B) mRNA level of A20 for VEC and A20 overexpression groups was analyzed by western blotting and the reverse transcription quantitative polymerase chain reaction. $\mathrm{NF}-\kappa \mathrm{B}$ protein expression was evaluated by (C) western blotting and (D) ELISA. The data are presented as the mean \pm standard deviation. ${ }^{*} \mathrm{P}<0.05$ vs. VEC group. LPS, lipopolysaccharide; NF- $\kappa \mathrm{B}$, nuclear factor NF- $\kappa \mathrm{B}$; VEC, vehicle control.

induced by LPS and reached a peak at $1 \mathrm{~h}$. Subsequently, the expression gradually reduced. However, the NF- $\kappa \mathrm{B}$ protein expression was significantly inhibited in A20 overexpressing macrophages (Fig. 4C and D).

The mRNA levels of TNF- $\alpha$ and IL- $1 \beta$ were upregulated in the VEC macrophages induced by LPS and were highest at $1 \mathrm{~h}$. (Fig. 5A and B). This result was the same as the levels of TNF- $\alpha$ and IL-1 $\beta$ measured by ELISA (Fig. 5C and D). However, the levels of TNF- $\alpha$ and IL-1 $\beta$ were significantly inhibited in the A20 overexpressing macrophages.

A20 overexpression increases $M$ polarization from $M 1$ to M2 phenotype. F4/80 and CD206 are expressed in macrophages (27). As presented in Fig. 6, macrophage phenotypes 

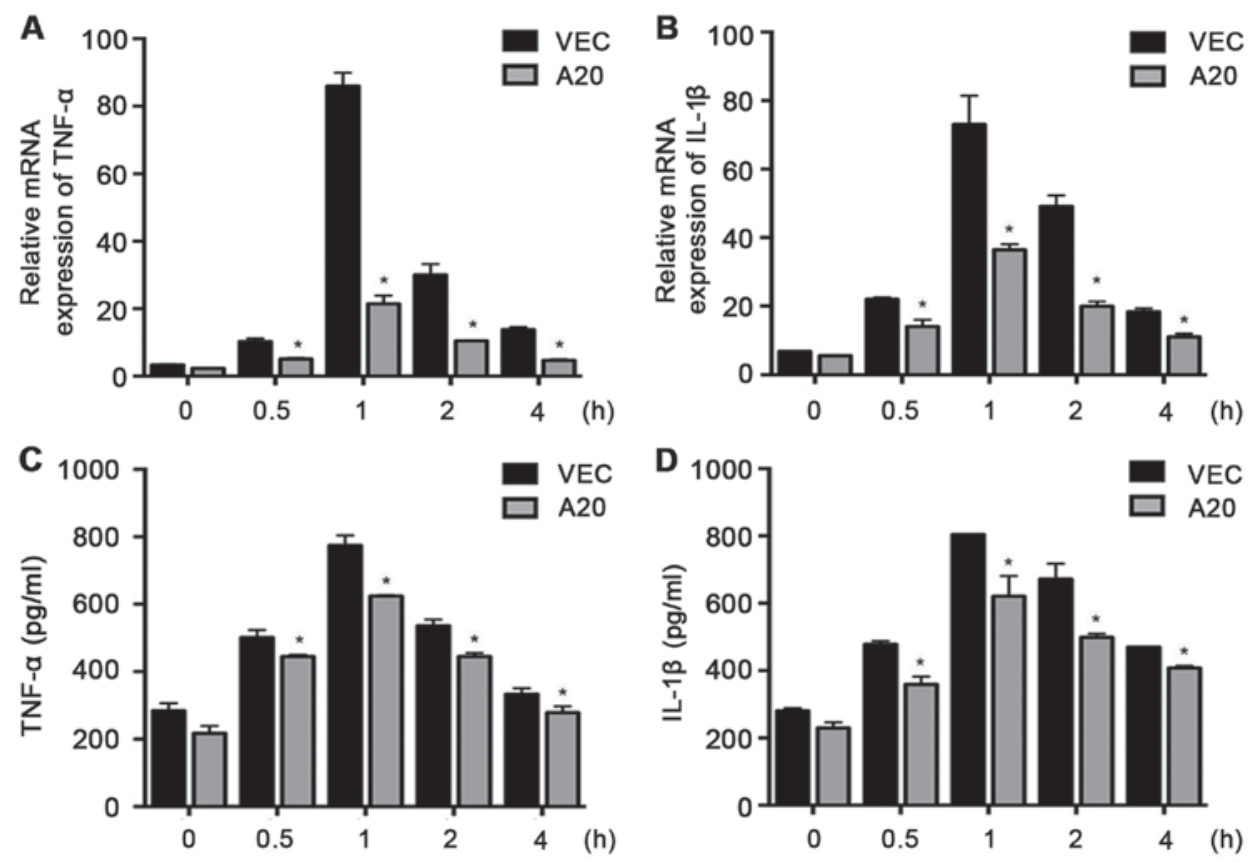

Figure 5. Effects of A20 overexpression on TNF- $\alpha$ and IL-1 $\beta$. mRNA levels of (A) TNF- $\alpha$ and (B) IL-1 $\beta$ were analyzed by reverse transcription quantitative polymerase chain reaction. Protein levels of (C) TNF- $\alpha$ and (D) IL-1 $\beta$. The data are presented as the mean \pm standard deviation. "P<0.05 vs. VEC group. TNF- $\alpha$, tumor necrosis factor $\alpha$; IL-1 $\beta$, interleukin $1 \beta$.
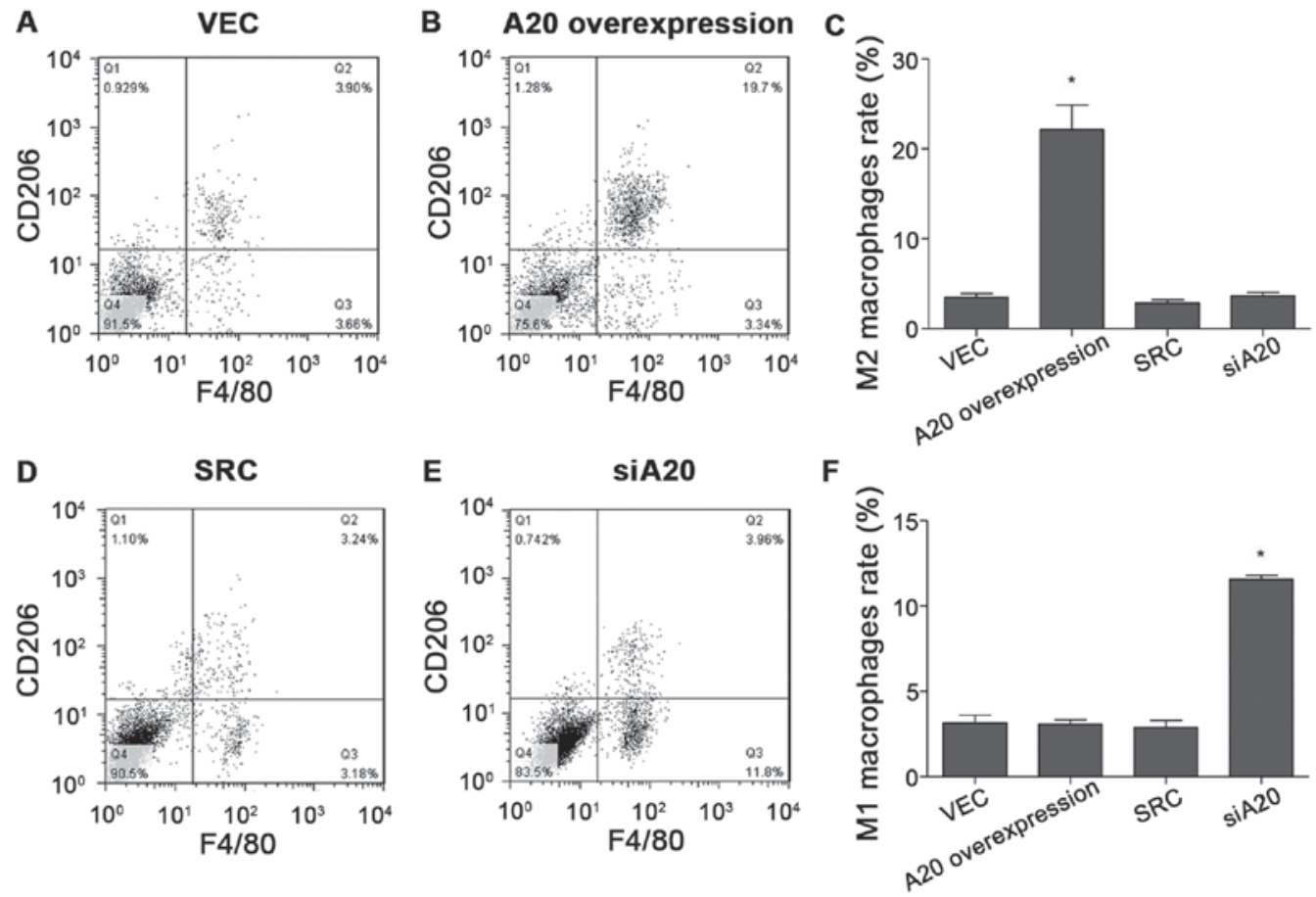

Figure 6. A20 overexpression increases macrophage polarization from the M1 to M2 phenotype in the NR8383 cell line following treatment with LPS. Flow cytometric analysis of cells in the (A) VEC and (B) A20 overexpression groups labeled with anti-CD206-APC and antiF4/80-FITC. (C) The percentage of M2 macrophages in the VEC, A20 overexpression, SCR and siA20 groups. Flow cytometric analysis of cells in the (D) SCR, (E) siA20 groups labeled with anti-CD206-APC and antiF4/80-FITC. (F) The percentage of M1 macrophages in the VEC, A20 overexpression, SCR and siA20 groups The percentage of cells stained with CD206 and F4/80 markers was calculated. The results are presented as the mean \pm standard deviation ( $\mathrm{n}=3$ ). ${ }^{*} \mathrm{P}<0.05$ vs. the respective control group. LPS, lipopolysaccharide; VEC, vehicle control; SCR, scrambled controlled RNA; siA20, small interfering RNA of A20; APC, allophycocyanin; FITC, fluorescein isothiocyanate.

were investigated using FACs. Macrophage phenotypes M2 and M1 were distinguished by FACS using diverse macrophages markers, F4/80 and CD206 in A20-knockdown and
A20-overexpressing NR8383 cells. The present data revealed $\mathrm{CD} 206^{+}$and $\mathrm{F} 4 / 80^{+}$cells in the A20-overexpressing macrophages in contrast with VEC cells (Fig. 6A and B), and CD206 ${ }^{+}$ 
and $\mathrm{F} 4 / 80^{+} \mathrm{A} 20$-knockdown macrophages compared with SRCs (Fig. 6D and E). The CD206 $/ \mathrm{F} 4 / 80^{+}$cells (representing M2 macrophages) and the CD206 $/ \mathrm{F} 4 / 80^{+}$cells (representing M1 macrophages) were assayed by FACS, and it was observed that LPS induced M1 macrophage polarization (Fig. 6C and F). It was concluded that A20-overexpression increased $\mathrm{M}$ polarization from the M1 to M2 phenotypes in the NR8383 cells treated with LPS.

\section{Discussion}

Macrophage-associated inflammation is a double-edged sword in acute lung injury, owing to its divergent polarization potential. However, molecular mechanisms and potential intervention strategies for macrophage polarization remain obscure. In the present study, the role of A20 protein in the $\mathrm{NF}-\kappa \mathrm{B}$ signaling pathway, macrophage polarization and acute lung injury, in vitro and in vivo, was demonstrated. The present results suggested that the A20 protein in macrophages could regulate LPS-induced lung injury through the $\mathrm{NF}-\kappa \mathrm{B}$ signaling pathway. It was further demonstrated that overexpression of A20 may be involved in the M2 polarization of macrophages. Therefore, the present study revealed that the inhibitory effect of A20 on the NF- $\mathrm{B}$ signaling pathway was associated with macrophage polarization.

Excessive activation of the $\mathrm{NF}-\kappa \mathrm{B}$ signaling pathway in macrophages may induce proinflammatory cytokine production, leading to tissue damage and inappropriate immune responses. In the present study, $N F-\kappa B$ and $T N F-\alpha$ were demonstrated to also be essential in LPS-induced lung injury. A20 is currently considered a negative regulator of inflammation $(20,29,30)$ and has been demonstrated to inhibit NF- $\kappa \mathrm{B}$ activity by disrupting the upstream ubiquitin complex (29). Previous studies have demonstrated that A20 inhibits NF- $\mathrm{B}$ activation and is associated with signaling pathways that are induced by TNF- $\alpha$ and IL-1 $\beta$ (30,31). Furthermore, an asthma mouse model demonstrated that A20 could attenuate allergic airway inflammation, which indicates a potential role of A20 in inflammatory lung diseases (32). The results of the present study also suggested that normal lung tissues demonstrated lower levels of A20 mRNA and protein. In addition, LPS stimulation increased the expression of A20, particularly in the early time points following treatment. It was also observed that shortly following in vitro LPS administration, the cultured NR8383 cells exhibited a high level of A20 expression. This indicated that acute injury induced by LPS could induce a rapid upregulation of intracellular A20 protein.

The results of the present study also proved the regulating role of A20 in the NF- $\mathrm{AB}$ signaling pathway and cytokine production. A20 was a crucial molecule in the regulation of $\mathrm{NF}-\kappa \mathrm{B}$ and TNF- $\alpha$ production in macrophages and the immunofluorescent staining demonstrated that A20 was expressed in pulmonary macrophages. Macrophages are involved in a number of immune disorders, and their infiltration into alveoli and release of a variety of proinflammatory cytokines are common pathogenic phenomena in airway inflammation (33). Following treatment with LPS, the level of ubiquitin enzyme A20 in macrophages was elevated but this was not sufficient to downregulate the production of proinflammatory factors, including TNF- $\alpha$ and IL-1 $\beta$ which could be causal cytokines for lung injury. It was also observed that the suppression of A20 induced an increase in the production of these proinflammatory factors in macrophages. The overexpression of A20 resulted in the suppression of $\mathrm{NF}-\kappa \mathrm{B}$ activation and TNF- $\alpha$ production in macrophages, and therefore, suppressed endothelial hyperpermeability in the lung.

Lung injury induced by LPS could be modulated by the A20 protein in macrophages. Therefore, progression of inflammatory disease may be delayed or inhibited if the activity of $\mathrm{NF}-\kappa \mathrm{B}$ was effectively inhibited by A20. Taking these results into account, A20-based therapy may be a promising treatment strategy for acute lung injury, as well as other inflammatory diseases.

As $N F-\kappa B$ is associated with macrophage polarization in inflammation, the expression of macrophage markers was also tested (F4/80 and CD206) in the present study. CD206 is a mannose receptor of $175 \mathrm{kDa}$, a type I membrane protein with a pattern recognition receptor domain of the C-type lectin superfamily. CD206 is expressed on M2 macrophages and serves an essential role in host defense, innate immunity and acquired immunity (15). In the present study, it was concluded that A20-overexpression enhanced macrophage polarization from the M1 to M2 phenotype in NR8383 cells treated with LPS.

Different phenotypes of activated macrophages have different significance in the inflammatory response. M1 macrophages may produce an acute inflammatory response and a large number of invasive inflammatory factors (19). At the same time, M2 macrophages are involved in tissue repair and wound healing, indicating the role of the inflammatory response in repair. A previous study demonstrated that the activation of the $\mathrm{NF}-\kappa \mathrm{B}$ signaling pathway is involved in the polarization of macrophages (14), which has a role in the immune regulation of ALI. The present study demonstrated that A20 overexpression could promote the polarization of macrophages and demonstrated that A20 could regulate ALI inflammation through the $\mathrm{NF}-\kappa \mathrm{B}$ signaling pathway. Therefore, A20 may be able to manipulate the polarization of macrophages to alter the level of inflammation and disease outcome. However, further studies are required.

In conclusion, the overexpression of A20 in macrophages may be involved in modulating macrophage polarization in lung injury, implying that A20 may have the potential to be used in interventions for LPS-associated lung disorders.

\section{Acknowledgements}

The present study was supported by grants from the National Natural Science Foundation of China (grant nos. 81300055, 81400043 and 81490530) and the Doctoral Fund of the Ministry of Education of China (grant no. 20130071110044). The project was supported by the Shanghai Committee of Science and Technology of China (grant no. 15DZ1930600), and by grant B115 from the Shanghai Leading Academic Discipline Project. Y.S. was supported by the Program for a Professor of Special Appointment (Eastern Scholar) at the Shanghai Institution of Higher Learning and the Key Medical grant from the Science and Technology Commission of Shanghai Municipality (grant nos. 11411951102 and 12JC1402300), and by the State Key Basic Research Program (973) project (grant 
no. 2015CB553404). C.B. was supported by the Research Fund for the Doctoral Program of Higher Education of China (grant no. 20110071110054). The authors of the present study would like to thank Mr Lei Gao, the technician of the Pulmonary Department of Zhongshan Hospital, Fudan University, for technical assistance.

\section{References}

1. ARDS Definition Task Force, Ranieri VM, Rubenfeld GD, Thompson BT, Ferguson ND, Caldwell E, Fan E, Camporota L and Slutsky AS: Acute respiratory distress syndrome: The Berlin definition. JAMA 307: 2526-2533, 2012.

2. Sheu CC, Gong MN, Zhai R, Bajwa EK, Chen F, Thompson BT and Christiani DC: The influence of infection sites on development and mortality of ARDS. Intensive Care Med 36: 963-970, 2010.

3. Writing Committee of the WHO Consultation on Clinical Aspects of Pandemic (H1N1) 2009 Influenza, Bautista E, Chotpitayasunondh T, Gao Z, Harper SA, Shaw M, Uyeki TM, Zaki SR, Hayden FG, Hui DS, et al: Clinical aspects of pandemic 2009 influenza A (H1N1) virus infection. N Engl J Med 362 $1708-1719,2010$

4. Thille AW, Esteban A, Fernández-Segoviano P, Rodriguez JM, Aramburu JA, Vargas-Errázuriz P, Martín-Pellicer A, Lorente JA and Frutos-Vivar F: Chronology of histological lesions in acute respiratory distress syndrome with diffuse alveolar damage: A prospective cohort study of clinical autopsies. Lancet Respir Med 1: 395-401, 2013

5. Guérin C, Reignier J, Richard JC, Beuret P, Gacouin A, Boulain T, Mercier E, Badet M, Mercat A, Baudin O, et al: Prone positioning in severe acute respiratory distress syndrome. $\mathrm{N}$ Engl J Med 368: 2159-2168, 2013.

6. Millar FR, Summers C, Griffiths MJ, Toshner MR and Proudfoot AG: The pulmonary endothelium in acute respiratory distress syndrome: Insights and therapeutic opportunities. Thorax 71: 462-473, 2016.

7. Horie S, Masterson C, Devaney J and Laffey JG: Stem cell therapy for acute respiratory distress syndrome: A promising future? Curr Opin Crit Care 22: 14-20, 2016.

8. Manicone AM: Role of the pulmonary epithelium and inflammatory signals in acute lung injury. Expert Rev Clin Immunol 5: $63-75,2009$

9. Castellheim A, Brekke OL, Espevik T, Harboe M and Mollnes TE: Innate immune responses to danger signals in systemic inflammatory response syndrome and sepsis. Scand J Immunol 69: 479-491, 2009.

10. Fan J, Ye RD and Malik AB: Transcriptional mechanisms of acute lung injury. Am J Physiol Lung Cell Mol Physiol 281: L1037-L1050, 2001

11. Chandel NS, Trzyna WC, McClintock DS and Schumacker PT: Role of oxidants in NF-kappa B activation and TNF-alpha gene transcription induced by hypoxia and endotoxin. J Immunol 165 : $1013-1021,2000$

12. Tak PP and Firestein GS: NF-kappaB: A key role in inflammatory diseases. J Clin Invest 107: 7-11, 2001.

13. Igarashi H, Yahagi A, Saika T, Hashimoto J, Tomita T, Yoshikawa $\mathrm{H}$ and Ishihara $\mathrm{K}$ : A pro-inflammatory role for A20 and ABIN family proteins in human fibroblast-like synoviocytes in rheumatoid arthritis. Immunol Lett 141: 246-253, 2012.

14. Porta C, Rimoldi M, Raes G, Brys L, Ghezzi P, Di Liberto D, Dieli F, Ghisletti S, Natoli G, De Baetselier P, et al: Tolerance and M2 (alternative) macrophage polarization are related processes orchestrated by p50 nuclear factor kappaB. Proc Natl Acad Sci USA 106: 14978-14983, 2009.

15. Sica A and Mantovani A: Macrophage plasticity and polarization: In vivo veritas. J Clin Invest 122: 787-795, 2012.

16. Mantovani A, Biswas SK, Galdiero MR, Sica A and Locati M: Macrophage plasticity and polarization in tissue repair and remodelling. J Pathol 229: 176-185, 2013.
17. Chen HI: From neurogenic pulmonary edema to fat embolism syndrome: A brief review of experimental and clinical investigations of acute lung injury and acute respiratory distress syndrome. Chin J Physiol 52 (5 Suppl): S339-S344, 2009.

18. Lucas R, Verin AD, Black SM and Catravas JD: Regulators of endothelial and epithelial barrier integrity and function in acute lung injury. Biochem Pharmacol 77: 1763-1772, 2009.

19. Murray PJ and Wynn TA: Obstacles and opportunities for understanding macrophage polarization. J Leukoc Biol 89: 557-563, 2011.

20. Lee EG, Boone DL, Chai S, Libby SL, Chien M, Lodolce JP and Ma A: Failure to regulate TNF-induced NF-kappaB and cell death responses in A20-deficient mice. Science 289: 2350-2354, 2000.

21. Huang L, Verstrepen L, Heyninck K, Wullaert A, Revets H, De Baetselier P and Beyaert R: ABINs inhibit EGF receptor-mediated NF-kappaB activation and growth of EGF receptor-overexpressing tumour cells. Oncogene 27: 6131-6140, 2008

22. Hitotsumatsu O, Ahmad RC, Tavares R, Wang M, Philpott D, Turer EE, Lee BL, Shiffin N, Advincula R, Malynn BA, et al: The ubiquitin-editing enzyme A20 restricts nucleotide-binding oligomerization domain containing 2 -triggered signals. Immunity 28 : 381-390, 2008

23. Gon Y, Asai Y, Hashimoto S, Mizumura K, Jibiki I, Machino T, Ra C and Horie T: A20 inhibits toll-like receptor 2- and 4-mediated interleukin-8 synthesis in airway epithelial cells. Am J Respir Cell Mol Biol 31: 330-336, 2004.

24. Tiesset H, Pierre M, Desseyn JL, Guéry B, Beermann C, Galabert C, Gottrand F and Husson MO: Dietary (n-3) polyunsaturated fatty acids affect the kinetics of pro- and antiinflammatory responses in mice with Pseudomonas aeruginosa lung infection. J Nutr 139: 82-89, 2009.

25. Onose A, Hashimoto S, Hayashi S, Maruoka S, Kumasawa F, Mizumura K, Jibiki I, Matsumoto K, Gon Y, Kobayashi T, et al: An inhibitory effect of A20 on NF-kappaB activation in airway epithelium upon influenza virus infection. Eur J Pharmacol 541: 198-204, 2006

26. Feng N, Wang Q, Zhou J, Li J, Wen X, Chen S, Zhu Z, Bai C, Song Y and Li H: Keratinocyte growth factor-2 inhibits bacterial infection with Pseudomonas aeruginosa pneumonia in a mouse model. J Infect Chemother 22: 44-52, 2016.

27. Yang G, Meng Y, Li W, Yong Y, Fan Z, Ding H, Wei Y, Luo J and Ke ZJ: Neuronal MCP-1 mediates microglia recruitment and neurodegeneration induced by the mild impairment of oxidative metabolism. Brain Pathol 21: 279-297, 2011.

28. Livak KJ and Schmittgen TD: Analysis of relative gene expression data using real-time quantitative PCR and the 2(-Delta Delta C(T)) method. Methods 25: 402-408, 2001.

29. Xiao X, Gaffar I, Guo P, Wiersch J, Fischbach S, Peirish L, Song Z, El-Gohary Y, Prasadan K, Shiota C and Gittes GK: M2 macrophages promote beta-cell proliferation by up-regulation of SMAD7. Proc Natl Acad Sci USA 111: E1211-E1220, 2014.

30. Shembade N, Ma A and Harhaj EW: Inhibition of NF-kappaB signaling by A20 through disruption of ubiquitin enzyme complexes. Science 327: 1135-L1139, 2010.

31. Song X, Yao Z, Yang J, Zhang Z, Deng Y, Li M, Ma C, Yang L, Gao X, Li W, et al: HCV core protein binds to gClqR to induce A20 expression and inhibit cytokine production through MAPKs and NF- $\kappa$ B signaling pathways. Oncotarget 7: 33796-33808, 2016.

32. Kang NI, Yoon HY, Lee YR, Won M, Chung MJ, Park JW, Hur GM, Lee HK and Park BH: A20 attenuates allergic airway inflammation in mice. J Immunol 183: 1488-1495, 2009.

33. Rakkestad KE, Holme JA, Paulsen RE, Schwarze PE and Becher R: Mono(2-ethylhexyl) phthalate induces both proand anti-inflammatory responses in rat alveolar macrophages through crosstalk between $\mathrm{p} 38$, the lipoxygenase pathway and PPARalpha. Inhal Toxicol 22: 140-150, 2010. 